\title{
Manufacture of Green-Composite Sandwich Structures with Basalt Fiber and Bioepoxy Resin
}

\author{
J. P. Torres, ${ }^{1}$ R. Hoto, ${ }^{2}{ }^{\text {J. Andrés, }}{ }^{3}$ and J. A. García-Manrique ${ }^{2}$ \\ ${ }^{1}$ Instituto de Ciencia y Tecnología de Materiales, Universidad Nacional de Mar del Plata, Av. J.B. Justo 4302, \\ B7608FDQ Mar del Plata, Argentina \\ ${ }^{2}$ Universidad Politécnica de Valencia, Camino Vera s/n, 46022 Valencia, Spain \\ ${ }^{3}$ Universitat Jaume I, Avenida de Vicent Sos Baynat, 12071 Castellón, Spain
}

Correspondence should be addressed to J. A. García-Manrique; jugarcia@mcm.upv.es

Received 8 March 2013; Accepted 7 May 2013

Academic Editor: Belal F. Yousif

Copyright (C) 2013 J. P. Torres et al. This is an open access article distributed under the Creative Commons Attribution License, which permits unrestricted use, distribution, and reproduction in any medium, provided the original work is properly cited.

\begin{abstract}
Nowadays, there is a growing interest for the use and development of materials synthesized from renewable sources in the polymer composites manufacturing industry; this applies for both matrix and reinforcement components. In the present research, a novel basalt fibre reinforced (BFR) bioepoxy green composite is proposed as an environmentally friendly alternative to traditional petroleum-derived composites. In addition, this material system was combined with cork as core material for the fabrication of fibre composite sandwich structures. Mechanical properties of both skin and core materials were assessed through flexural and tensile tests. Finite element (FEM) simulations for the mechanical stress analysis of the sandwich material were carried out, and a maximum allowable shear stress for material failure under bending loads was established. Permeability measurements of the basalt fabrics were carried out in order to perform numerical simulations of liquid composite moulding (LCM) processes on the PAMRTM software. The proposed green-composite sandwich material was used for the fabrication of a longboard as a case study for a sports equipment application. Numerical simulations of the mould filling stage allowed the determination of an optimal mould filling strategy. Finally, the load-bearing capacity of the board was studied by means of FEM simulations, and the presented design proved to be acceptable for service.
\end{abstract}

\section{Introduction}

Nowadays, there is a growing need for the production and development of materials synthesized from renewable sources and to decrease the world's dependence on petroleum. In the fiber reinforced polymer composites (FRPCs) manufacturing industry, these tendencies have recently led to the investigation of possible substitutes, both for matrix and reinforcement components. Recently, biobased matrix materials have received considerable attention mainly for being nonpetroleum-dependent. These systems can be obtained from sustainable sources such as vegetable oil, cellulose, and soy protein, among others. In the case of bio-based thermosetting resins, much research is still pending since mechanical properties comparable with those of petroleum-based counterparts are very difficult to achieve [1]. One of the main drawbacks of using plant oil as a precursor for bio-based resins is that its chemistry can lead to a low crosslink density network which produces a polymer with low glass transition temperature (lower than $90^{\circ} \mathrm{C}$ ), poor stiffness (lower than $2 \mathrm{GPa}$ ), and inferior thermophysical properties, compared to the traditional petroleumbased polymers. However, this same feature can lead to a superior toughness by providing additional deformation mechanisms for energy absorption before failure in impact loading situations [2]. Altogether, a compromise solution can be the combination of both synthetic and bio-based materials $[3,4]$ in such a way that a superior material is obtained from a cost-performance standpoint.

With respect to fiber reinforcements, basalt fibers (BFs) have been recently studied as sustainable alternative for fiber reinforcement since the earth has practically unlimited basalt reserves [5]. BFs are produced from basalt rock, the most common rock found in the earth crust. Also, 
basalt is biologically inert, and its weathering increases the mineral content of soil. BFs are manufactured by melting at $1300-1700^{\circ} \mathrm{C}$ and subsequent spinning. This manufacturing process requires no precursor or additives, which results in a decrease of its environmental impact and production costs [6]. Regarding mechanical performance, it has been reported that BFs have higher modulus and strength than glass fibers (GFs) [7]. In addition, basalt has much higher chemical resistance than glass: it can be used for the transportation and storage of corrosive liquids and gases. It also provides much better electrical insulating properties and thermalstability than glass [6]. Other advantages of basalt are its high UV radiation and seawater resistance. Finally, reduction of risk of environmental pollution like high-toxic metals and oxides can be achieved by replacing GFs with BFs. All of these features make BFs a suitable substitute for GFs. On the other hand, when comparing BFs against carbon fibers (CFs), BFs are more attractive from an environmental protection perspective since they offer sustainability and independence from petroleum at significantly lower costs (even though they have lower strength and stiffness). Finally, it is important to remark that basalt fiber interface interaction with polymeric resins is not completely understood [7] and a subject of further investigation in order to gain a precise knowledge of its effect on mechanical properties.

The objective of this paper is to investigate the possibility of using a novel BFR bio-based epoxy green composite system as a potential substitute for traditional petroleum-derived composites. For this, composite panels were manufactured using the VARTM technique. Also, sandwich-structured panels were made combining the green composite for the sandwich skin, with natural cork for the sandwich core. Mechanical behaviour of the proposed material system was assessed by means of flexural and uniaxial tensile tests together with FEM simulations. To perform numerical simulations of the processing stage, the fiber permeability was measured using an especially designed characterization setup. A case study for the fabrication of a sandwich-structured sports longboard was carried out. The fabrication stage was modelled using the PAM-RTM software along with the permeability values determined experimentally. The load-bearing capability of the board was studied by means of FEM stress analysis, and the board dimensions were determined in order to satisfy the maximum allowable stress values established in the mechanical characterization stage.

\section{Materials and Methods}

2.1. Overview on Liquid Composite Molding (LCM) Manufacturing Methods. LCM is a manufacturing method that consists in the impregnation of a fabric with a low viscosity resin. It is currently considered as one of the most viable and ecofriendly process in the manufacturing of high quality parts. Depending on the characteristics of the mould and the applied pressure gradient, there are a number of different types of LCM process among which are Resin Transfer Moulding (RTM), Vacuum Assisted Resin Transfer Moulding (VARTM), Reactive Injection Moulding (RIM),

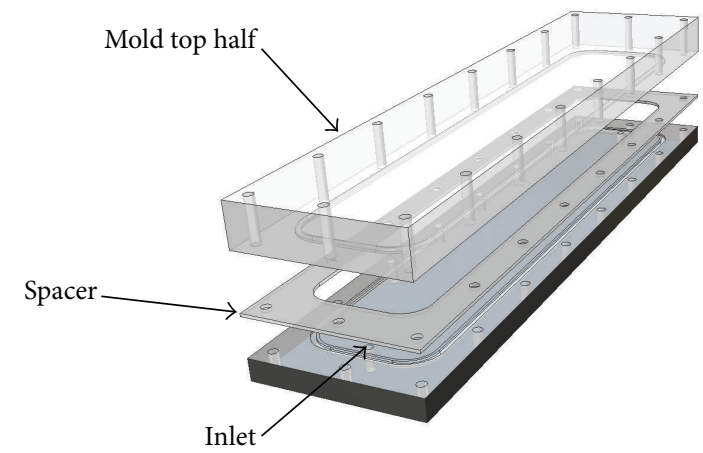

FIGURE 1: Mould assembly for the characterization of fiber preform permeability.

and Structural Reactive Injection Moulding (SRIM). One disadvantage in LCM methods is that defects such as voids and dry spots can be induced during the impregnation stage [8]. These defects are considered to be the largest source of quality and reproducibility problems. They are often caused by unbalanced resin flows, which are directly related to the fiber permeability and the impregnation velocity. As a consequence, an accurate prediction of resin flow behaviour in the fiber impregnation process is of great importance for the optimization of LCM parts quality. Currently, there are a number of computer simulation tools available for the modelling of LCM processes, which provide a remarkable advantage over the (cost and time consuming) trial-anderror methods traditionally used in the industry. In order to perform LCM modelling, one of the most critical input parameters for the mathematical models is the reinforcement permeability. In the past 20 years, a number of studies [9-11] have focused on the development of a reliable and standardized procedure for the accurate characterization of fiber permeability.

\subsection{Experimental Setup for Permeability Measurements.} Figure 1 shows the basic design of the experimental setup used for the unidirectional measurement of permeability. The bottom half of the mould was machined from a $1000 \times$ $280 \times 25 \mathrm{~mm}$ aluminium plate. The length of the mould was chosen according to the concept of "Minimum Injection Length" developed by Ferland et al. [10]. For the inlet and vent, two threaded holes (10 $\mathrm{mm}$ diameter) were machined and fitted with secure hydraulic connectors. The top-half of the mould was made from a machined methacrylate plate to allow visual observation of the flow front advance during experiments. The inner mould cavity consists of a $3 \mathrm{~mm}$ spacer and a rectangular silicon gasket to provide sealing. The entire mould assembly was then placed in a specially designed hydraulic press with a maximum clamping force of 5 tonnes (Figure 2). The top-half was mounted on a special frame which permits vertical displacement for the mould opening and closing operations.

A low cost data acquisition device (DATAQ DI-194RS), together with a high accuracy pressure transducer (mounted 


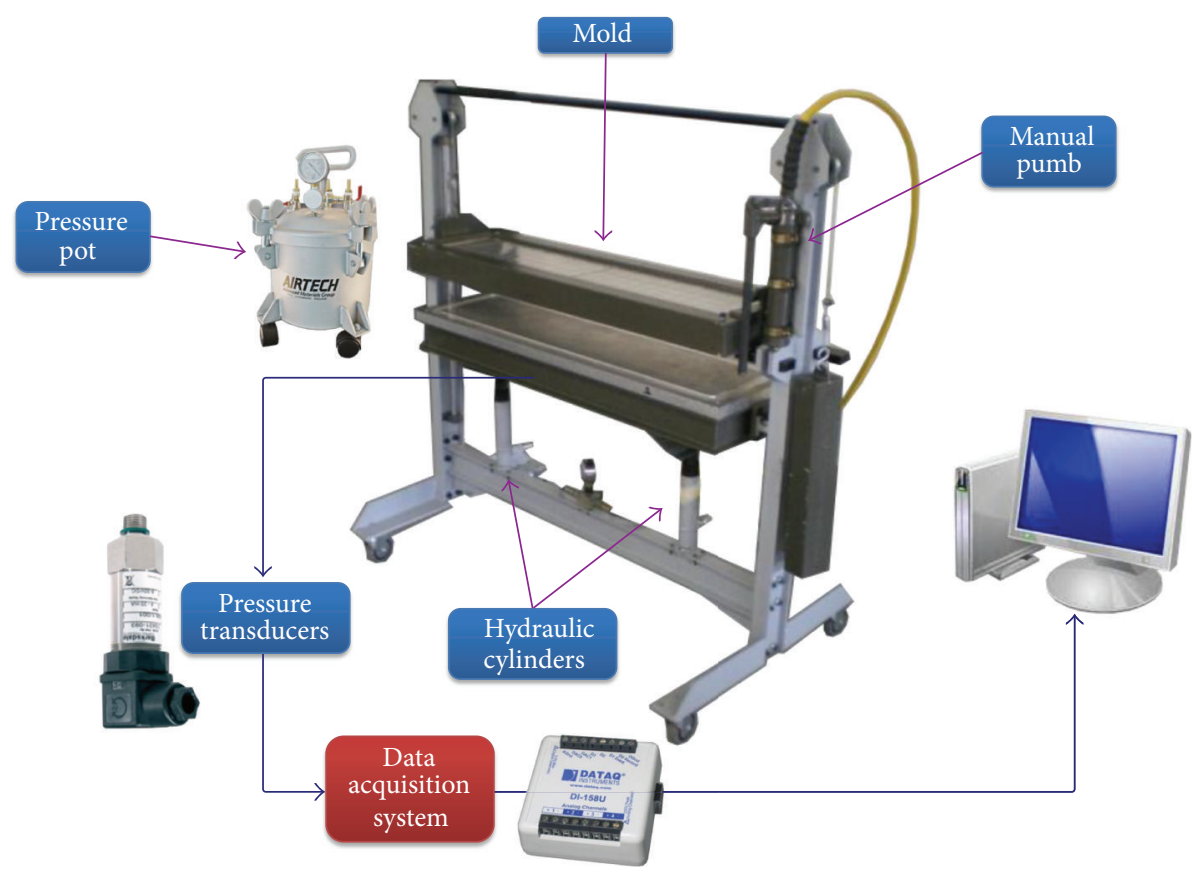

FIGURE 2: Setup for permeability measurements.

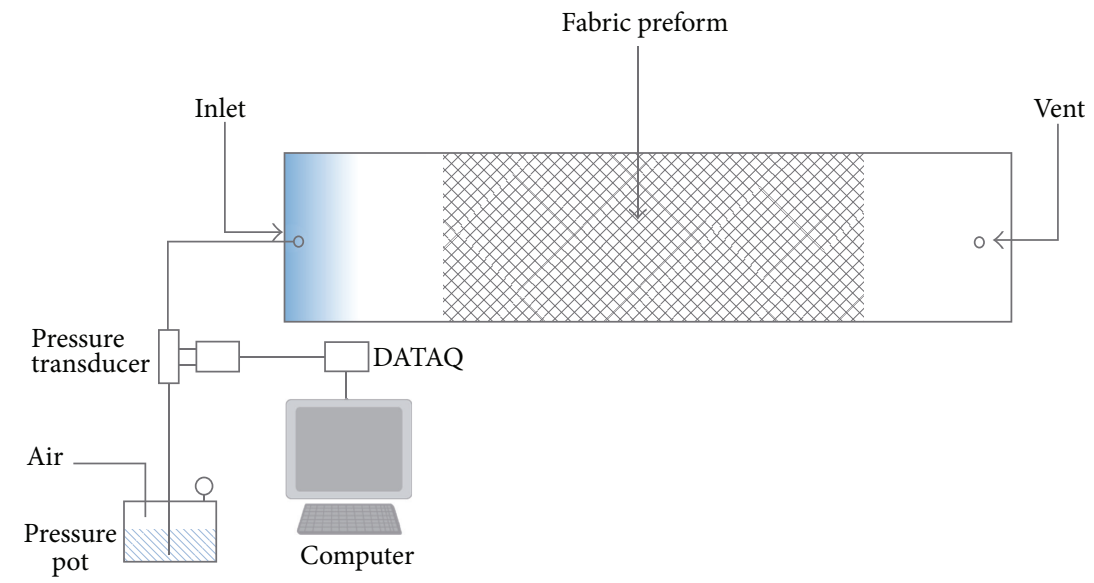

FIGURE 3: Schematic representation of the experimental setup.

on a " $\mathrm{T}$ " fixture), was used to measure the exerted pressure near the inlet gate of the mould (Figure 3). The DI-194 RS card was connected through a digital channel to a manual trigger which allowed manual scanning of the flow front progression. As a consequence, value pairs for the inlet pressure and flow front position could be measured at different time intervals. These recorded values were then used in the derivation of fiber permeability following the procedure established in [9].

2.3. Manufacturing of Green Composite and Sandwich Panels. For the present work, BFR bio-based epoxy green composites were manufactured using the VARTM technique. The fabric preform was placed over a glass tool previously coated with a release agent. Then, the reinforcements were covered with the peel ply, the bleeder material, and finally the plastic bag. The plastic bag is attached to the glass tool using double side tape. This provides a perfect seal for the whole arrangement. An inlet tube is placed for resin infusion, and finally, an outlet tube, connected to a vacuum pump, provides the channel both for excess resin and for air evacuation. $500 \mathrm{~mm} \times 900 \mathrm{~mm}$ plates were made using 8 plies of plain weave 6 basalt fabric laminates and the SUPER SAP 100/1000 biobased epoxy (made by Entropy Bio-Resins Co [12]. This epoxy resin is made from up to $37 \%$ biocontent obtained as coproducts of other green industries such as wood pulp and biofuels production. The resin has a total calculated biomass of $50 \%$ [13]. The resulting panels had a $2 \mathrm{~mm}$ thickness. After demoulding, the panels were cured at ambient temperature for 24 hours, followed by curing at $50^{\circ} \mathrm{C}$ for two hours in an electrical furnace. 
TABLE 1: Configuration for mechanical tests.

\begin{tabular}{lccc}
\hline Test type & Thickness $(\mathrm{mm})$ & Width $(\mathrm{mm})$ & Length $(\mathrm{mm})$ \\
\hline Compression (cork) & 5.0 & 20 (diameter) & - \\
Tensile (BFPC) & 2.0 & 25 & 180 \\
Flexural (BFPC) & 2.0 & 22 & 60 (support span) \\
Flexural (sandwich) & 7.0 & 22 & 60 (support span) \\
\hline
\end{tabular}

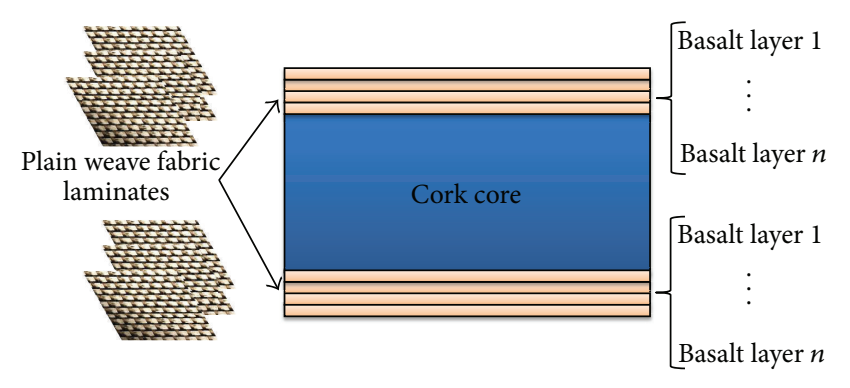

FIGURe 4: Composite sandwich structure panel.

On the other hand, sandwich-structured composites panels were also manufactured. Sandwich structured composites are a special class of composite materials which consist of thin high strength skins bonded to a thicker light weight core (Figure 4). This configuration provides high bending stiffness while keeping an overall low density. These properties, together with wide design versatility, make sandwich structured composites a choice of great interest in the field of LCM manufactured FRPC [14]. In the present investigation, a green-composite sandwich structure is proposed for the manufacturing of sandwich panels for engineering applications requiring flexural stiffness at low weight. Cork and a BFR bio-based composite were used as core and skin materials, respectively. The sandwich panels were made using the VARTM technique. For this, a two-layered BFR bioepoxy skin and a $5 \mathrm{~mm}$ thickness cork core were used.

2.4. Mechanical Characterization and FEM Simulations. In order to determine the mechanical properties of the basalt fibre bioepoxy composites, tensile and flexural coupons were obtained by waterjet cutting of VARTM manufactured flat panels. Cork compression samples were obtained from cork panels using a puncher. All mechanical tests were performed on an INSTRON 3365 testing machine (Figure 5). Table 1 shows specimen dimensions employed in every case.

In order to assess the stress states developed in the sandwich material under flexural loads, FEM simulations of the flexural test were carried out in ABAQUS/Implicit 6.10. This study will later serve as a validation stage in the design process for the optimization of part geometry and sandwich configuration for an actual part, as discussed in Section 4 . The flexural test was modelled using SC8R8-node quadrilateral continuum shell elements for the basalt fiber skin and C3D8R 8 -node linear brick element for the cork core. The supports and loading tip were modeled as analytical solids. Contact interaction properties were simplified assuming frictionless behavior and "hard" contact normal behavior. Figure 6 shows the part geometry and mesh distribution employed. The cork material was modelled as an isotropic hyperelastic material using the hyperfoam option in ABAQUS. The basaltreinforced skin was modelled as a linear orthotropic solid. Material parameters employed are shown in Table 2, and Poisson's ratio values were obtained from the literature [5].

\section{Results and Discussion}

3.1. Mechanical Properties and Stress Analysis. Mechanical properties for each material are presented in Table 2. For the BFPC, linear elastic response with brittle rupture was observed as expected (Figure 7(a)). Flexural testing on BFPC showed a linear response up to a point where stress starts to present small and continuous drops (Figure $7(\mathrm{~b})$ ). It was observed that these drops corresponded to material failure occurring in the upper face of the test coupon, which is under a compressive stress state (Figure 8).

Flexural testing of the composite sandwich showed a nonlinear stress-strain evolution up to a point where there is a significant stress drop followed by an approximately constant stress region (Figure 9). This point corresponds to material failure associated with shear failure of the cork core material as can be seen in Figure 10. Figure 11(a) shows the finite element results for the simulation of the test along with a representation of the corresponding normal stress profile along the symmetry plane of the sample (plane $y z$, where $z$ is the loading axis). Shear stresses in the cork core are approximately homogeneous in the thickness, while they are assumed negligible in the skin material since it was modeled as a shell. Figure 11(b) shows the evolution of shear stresses in the cork material as a function of distance from the axis of symmetry. Its value is 0 along the symmetry plane and increases to a maximum value located at approximately the middle point between the loading tip and the support. This fact is also confirmed in the observations of tested samples (Figure 11). Both Figures 11(a) and 11(b) are very useful for understanding how stress and deformation distribution occur in composite sandwich under flexural loads. For the purpose of mechanical design, a maximum allowable shear stress $\left(\tau_{\max }\right)$ assumption was made. This simplification arises from the fact that, for the intended application, the sandwich structure will carry predominantly flexural loads. A critical value of $33 \mathrm{MPa}$ for the shear stress in the cork core was obtained from the finite element simulation shear stress profile. 


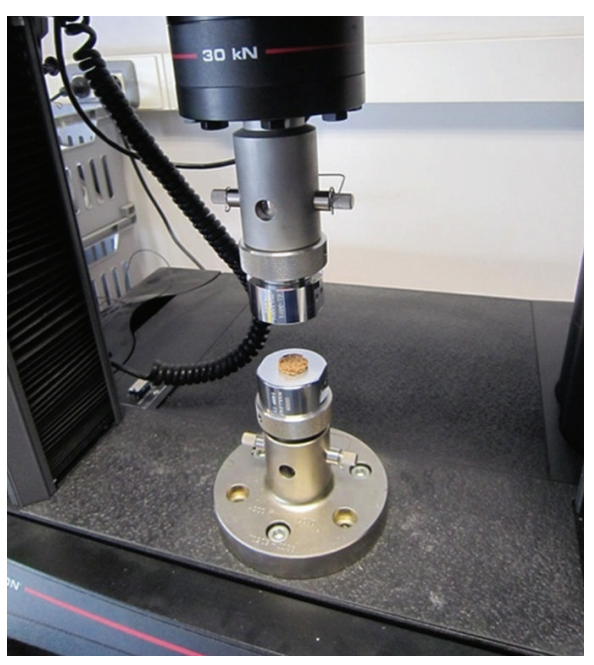

(a)

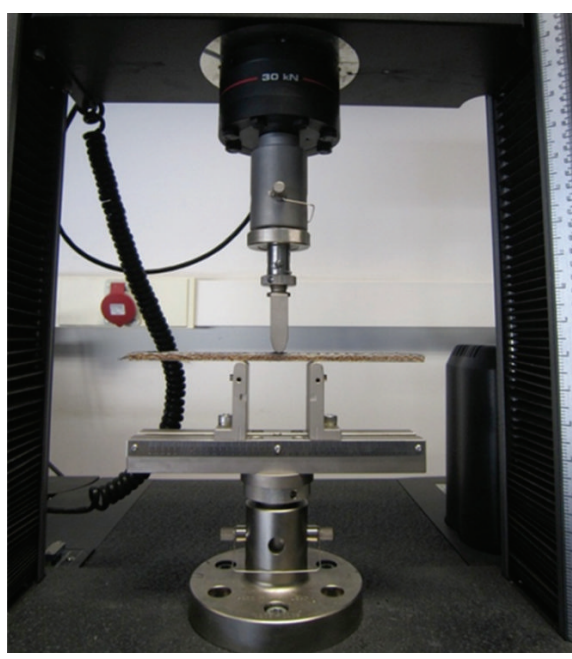

(b)

Figure 5: (a) Setup for compression testing of cork. (b) Specimen configuration for flexural testing of the composite sandwich.

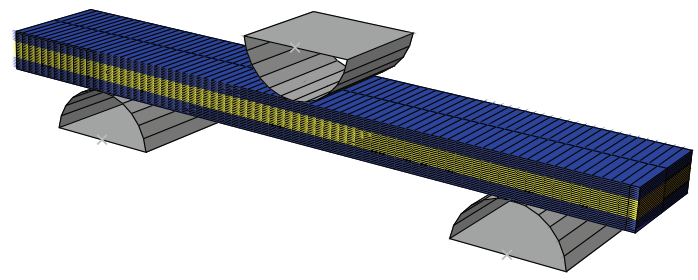

FIGURE 6: Finite element mesh used for the simulation of the 3 pointbending flexural tests.

TABLE 2: Mechanical properties obtained for sandwich components.

\begin{tabular}{lcc}
\hline Test type & $\begin{array}{c}\text { Young modulus } \\
(\mathrm{MPa})\end{array}$ & $\begin{array}{c}\text { Strength } \\
(\mathrm{MPa})\end{array}$ \\
\hline Compression (cork) & 4.5 & - \\
Tensile (BFPC) & 54,776 & 513 \\
Flexural (BFPC) & 56,455 & 462 \\
\hline
\end{tabular}

\section{Case Study: Manufacturing and Stress Analysis of a Green-Composite Sandwich Longboard}

The proposed green-composite sandwich system was studied as an environmentally sustainable alternative material for a sports equipment application, namely, longboarding. Longboards consist of a specially designed board, which have the same shape as skateboards but are longer (up to $120 \mathrm{~cm}$ ). Longboards are nowadays frequently used as an ecofriendly way to move around the city.

In order to choose the proper manufacturing strategy, two-dimensional flow simulations were performed using the commercial software PAM-RTM. The principal permeability [11] values $\left(K_{1}=1.56 E-11 \mathrm{~m}^{2}\right.$ and $\left.K_{2}=1.49 E-11 \mathrm{~m}^{2}\right)$ determined from the permeability measurements were employed. The bioepoxy resin viscosity was obtained from the supplier technical data sheet [12]. The part was modelled as a sandwich laminate composed by 4 layered upper and bottom skins and a $5 \mathrm{~mm}$ cork panel as core material. Two mould filling strategies were tested. In the first one (see Figure 12, left) the inlet is the symmetrical axis perpendicular to the longitudinal axis of the longboard, which leads to a larger resin path to complete the filling process. The second strategy, consisting of a longitudinal inlet oriented parallel to the axis of the board, conducts to a shorter resin path (see Figure 12, right). The simulation results show that, as it was expected, the second strategy is the most appropriate because it gives a shorter filling time. In the first filling strategy, the filling time exceeded the resin gel time (22 min-when crosslinking begins to dominate the nature of the resin and it solidifies into a gel-. Therefore, this strategy was discarded.

On the other hand, the second strategy leads to a total filling time of about 12 minutes. The final part quality of the resulting polymerized skins was assessed by scanning electron microscopy (SEM). SEM micrographs (Figure 14) showed complete fiber impregnation and total absence of voids both at the macroscale (between the bundles) and at microscale (inside bundles). Figure 13 shows the final part obtained after curing for 24 hours at ambient temperature before demolding and then cured in an oven at $50^{\circ} \mathrm{C}$. The final part was obtained by milling the longboard shape with a CNC machine.

Stress analysis for the longboard under loading conditions was performed by running finite element simulations on ABAQUS/Explicit 6.10. The failure criteria presented in the previous section was used to evaluate the mechanical stability of the longboard. An extreme loading situation was modelled considering the fall of a $90 \mathrm{~kg}$ weight person from a 1-meter height over the board. This was simplified by applying two loads, over an area approximately equal to the size of a shoe, in the two points midway between the center and 


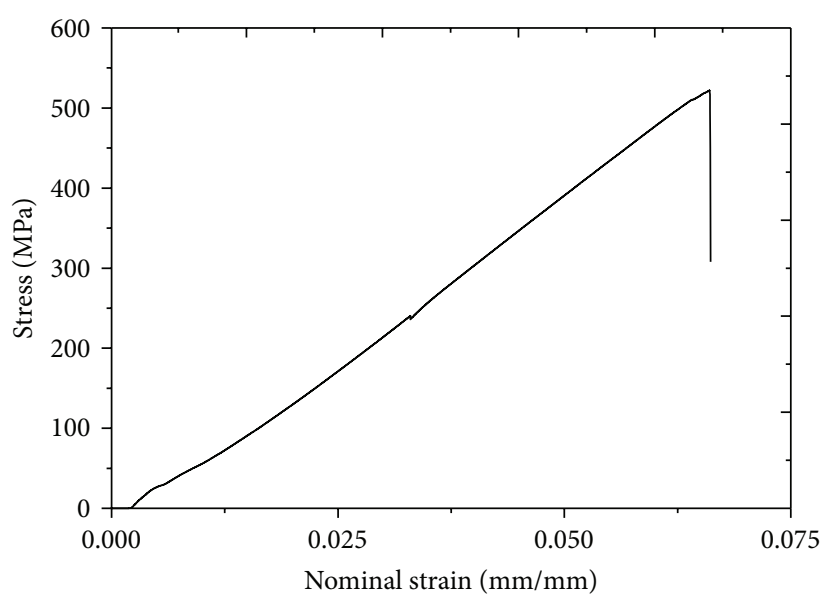

(a)

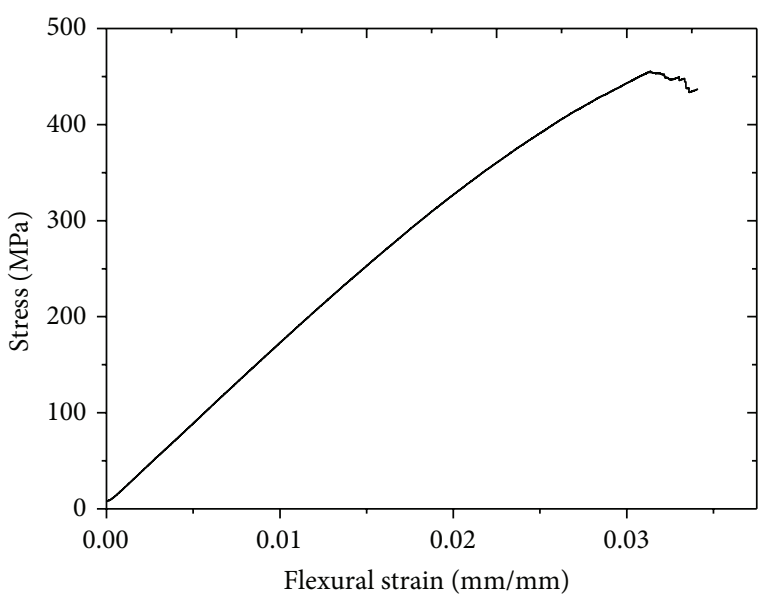

(b)

FIGURE 7: Stress-strain curves for BFPC: (a) tensile test; (b) flexural test.

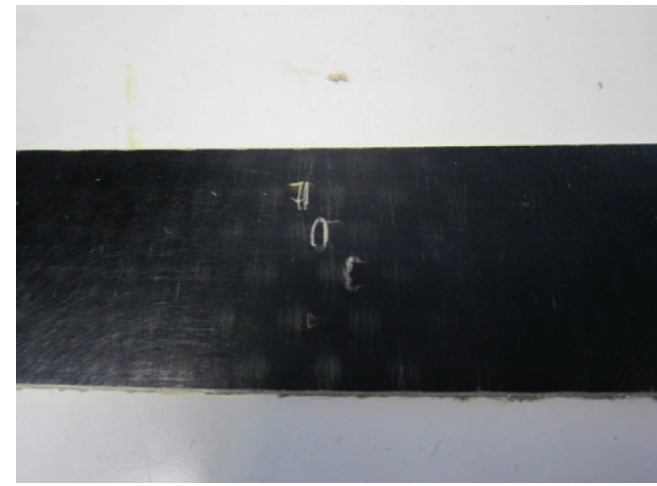

(a)

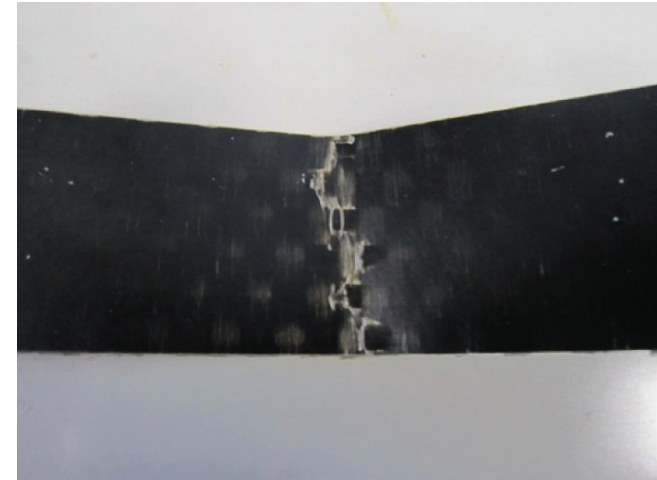

(b)

FIGURE 8: Successive stages of BFPC compressive failure in flexural tests.

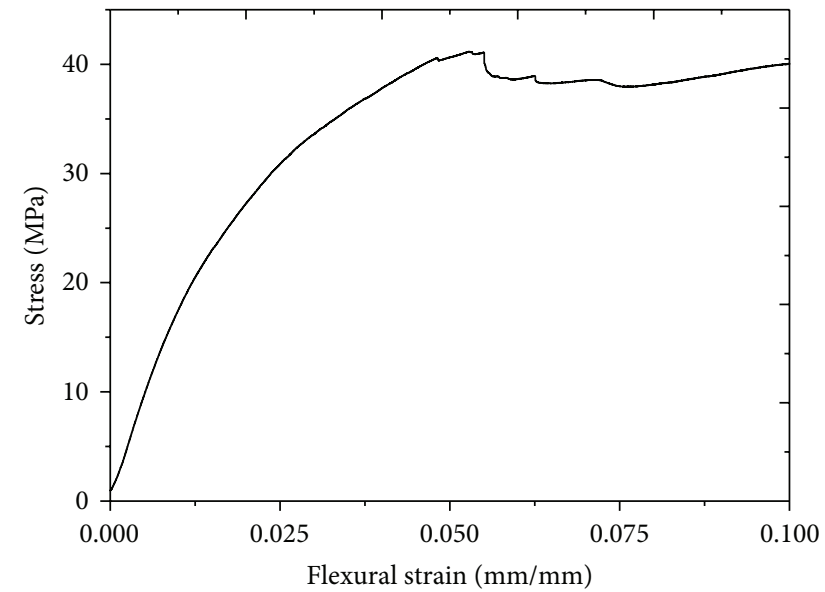

FIGURE 9: Stress-strain results for the composite sandwich flexural test.

the end of the part. The resulting stress distribution is shown in Figure 15. The stress analysis allows for the determination of the skin thickness by providing a lower bound below

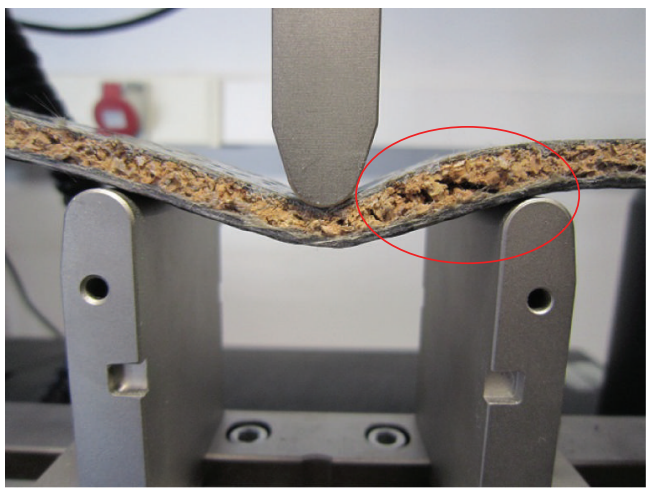

FIGURE 10: Critical failure of the sandwich sample by shear cavitation in the cork core.

which deflections are so large that the cork core fails by shear cavitation. For the designed longboard, a 1mm skin thickness resulted admissible since it leads to a maximum shear stress 5 times lower than the maximum allowed value determined previously. 


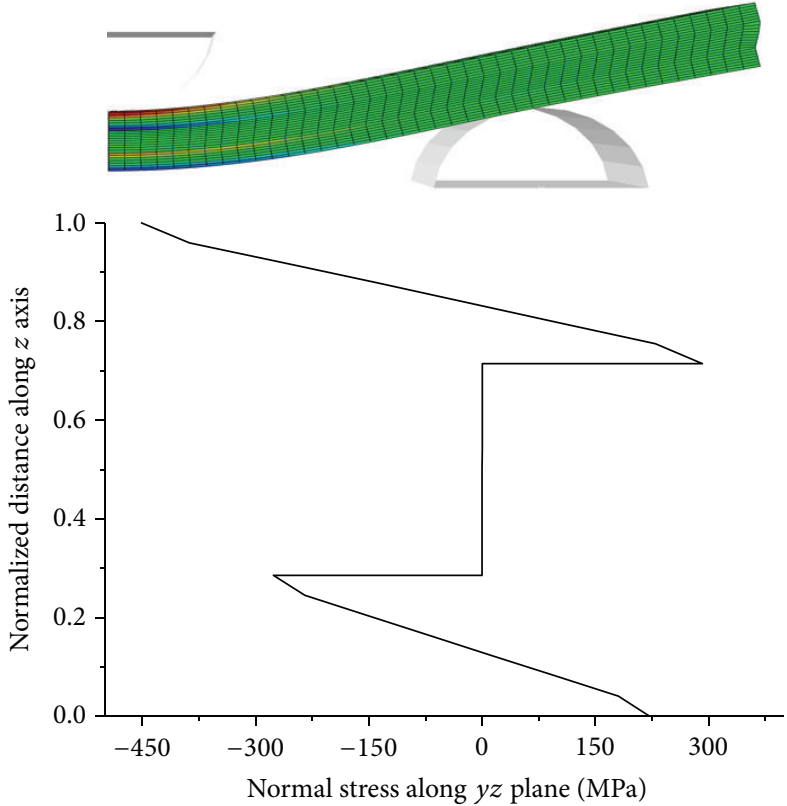

(a)
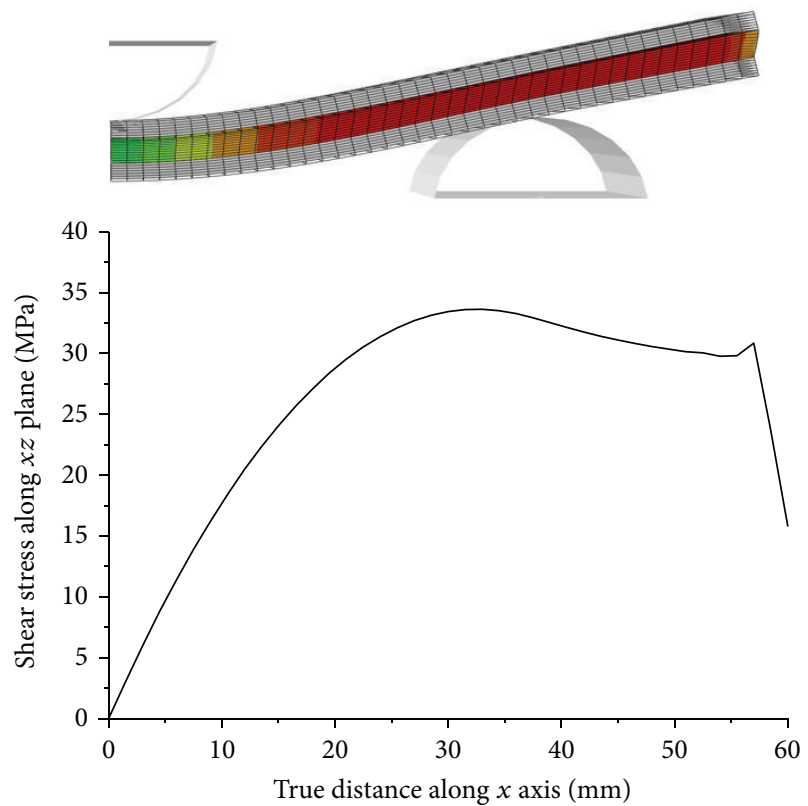

(b)

FIGURE 11: (a) Normal stress profile along the symmetry plane. (b) Shear stress evolution along the $x$ axis in the cork core.

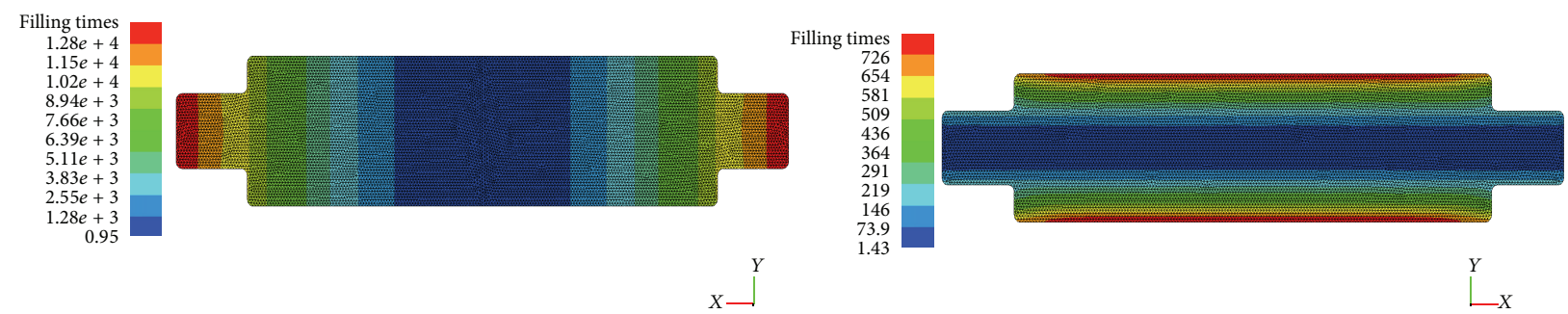

(a)
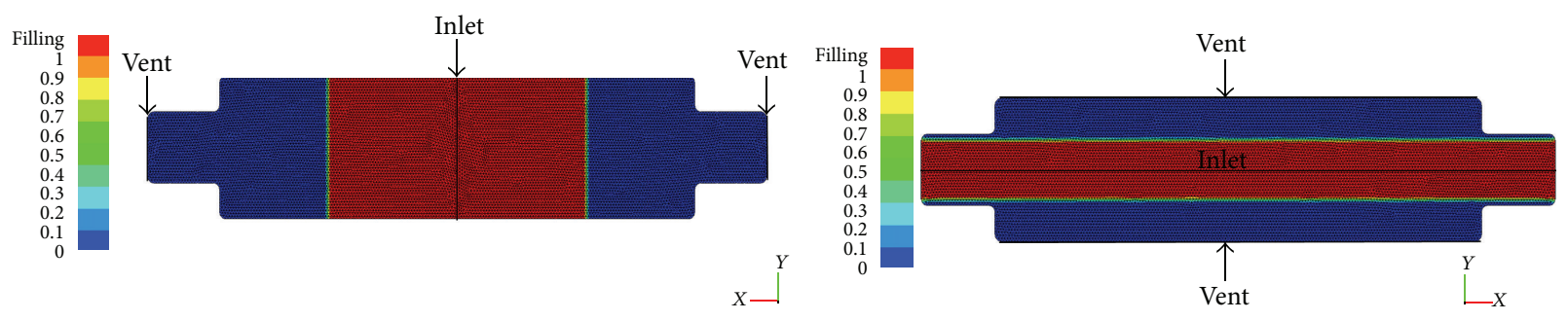

(b)

FiguRE 12: PAM-RTM simulation results for the two resin infusion strategies proposed for the fabrication of a longboard: (a) filling time; (b) flow front direction.

\section{Conclusions}

A novel BFR bioepoxy green composite is proposed as an environmentally friendly alternative to traditional petroleum-derived composites. This green composite was combined with natural cork as core material for the fabrication of sandwich-structured composite parts. Mechanical performance under tensile and flexural loads of the sandwich and its separate constituents was assessed on an INSTRON machine. It was found that the critical material failure mode is associated with cork shear rupture. As a consequence, FEM simulation results were used to determine a maximum allowable shear stress for its later use on design of sandwich parts.

As a case study for the manufacturing and performance of the material under service conditions, a longboard part was manufactured using the VARTM technique. The results from the permeability characterization allowed for the simulation of the mould filling stage. It was found that a complete filling with absence of defects could be accomplished by employing 


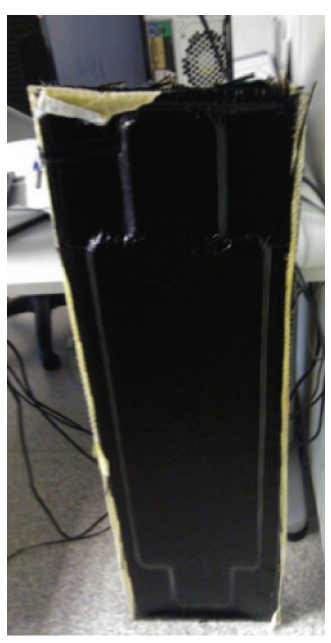

(a)

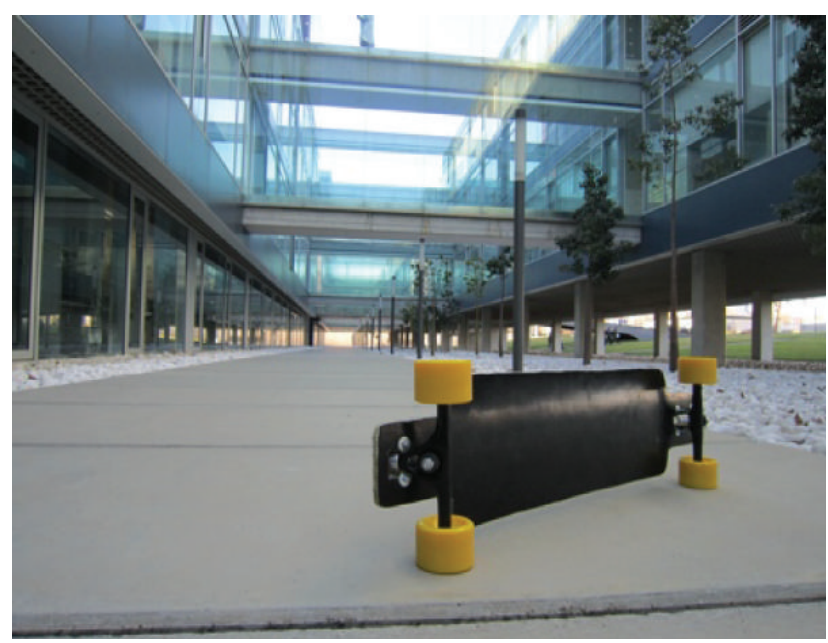

(b)

FIGURE 13: Longboard before demoulding and final obtained part.

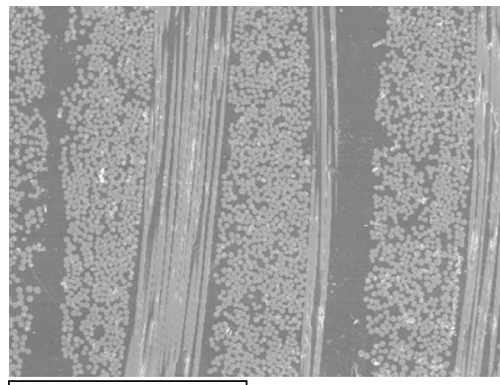

$600 \mu \mathrm{m}$

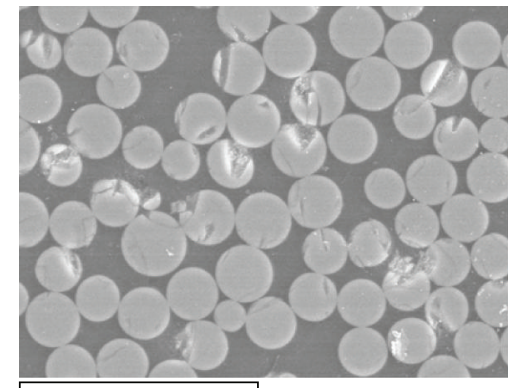

$60 \mu \mathrm{m}$

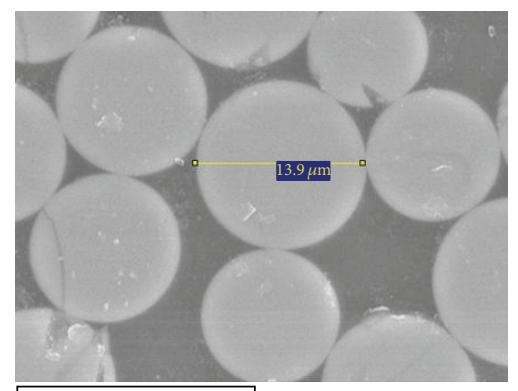

$20 \mu \mathrm{m}$

(a)

(b)

(c)

FIGURE 14: SEM micrograph taken from the polymerized samples showing complete fiber impregnation and the absence of voids.
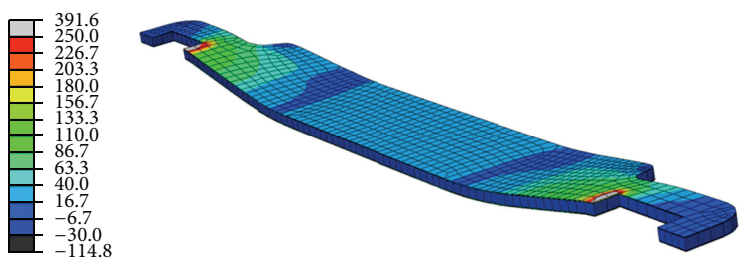

(a)

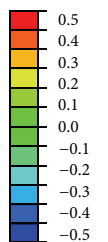

$-0.5$

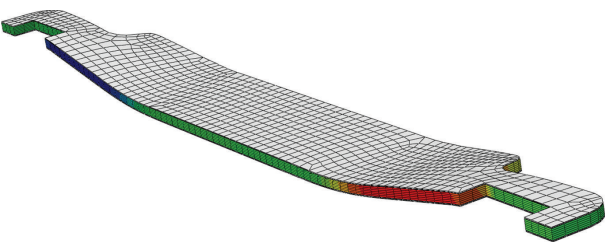

(b)

FIGURE 15: Simulation results for the longboard under normal service loads: (a) principal stress value; (b) shear stress distribution.

a longitudinal inlet parallel to the axis of the board. Stress analysis of the board was assessed by FEM simulations and the proposed design proved to satisfy the failure criteria and be acceptable for service conditions.

\section{Acknowledgments}

This research work is supported by the Spanish Ministerio de Ciencia e Innovación, Project DPI2010-20333, and the Generalitat Valenciana through Programme PROME$\mathrm{TEO} / 2009 / 063$.

\section{References}

[1] X. Q. Liu, W. Huang, Y. H. Jiang, J. Zhu, and C. Z. Zhang, "Preparation of a bio-based epoxy with comparable properties to those of petroleum-based counterparts," Express Polymer Letters, vol. 6, no. 4, pp. 293-298, 2012.

[2] D. Ratna, "Mechanical Properties and Morphology of epoxidized syabean-oil-modified epoxy resin," Polymer International, vol. 50, pp. 179-184, 2001.

[3] M. Haq, R. Burgueño, A. K. Mohanty, and M. Misra, "Processing techniques for bio-based unsaturated-polyester/clay 
nanocomposites: tensile properties, efficiency, and limits," Composites A, vol. 40, no. 4, pp. 394-403, 2009.

[4] H. Miyagawa, A. K. Mohanty, R. Burgueño, L. T. Drzal, and M. Misra, "Novel biobased resins from blends of functionalized soybean oil and unsaturated polyester resin," Journal of Polymer Science B, vol. 45, no. 6, pp. 698-704, 2007.

[5] Q. Liu, Basalt fiber reinforced polymer composites [Ph.D. thesis], University of Connecticut, 2006.

[6] V. Fiore, G. Di Bella, and A. Valenza, "Glass-basalt/epoxy hybrid composites for marine applications," Materials and Design, vol. 32, no. 4, pp. 2091-2099, 2011.

[7] V. Lopresto, C. Leone, and I. De Iorio, "Mechanical characterisation of basalt fibre reinforced plastic," Composites Part B, vol. 42, no. 4, pp. 717-723, 2011.

[8] J. A. García, L. Gascón, E. Cueto, I. Ordeig, and F. Chinesta, "Meshless methods with application to Liquid Composite Molding simulation," Computer Methods in Applied Mechanics and Engineering, vol. 198, no. 33-36, pp. 2700-2709, 2009.

[9] R. Arbter, J. M. Beraud, C. Binetruy et al., "Experimental determination of the permeability of textiles: a benchmark exercise," Composites A, vol. 42, no. 9, pp. 1157-1168, 2011.

[10] P. Ferland, D. Guittard, and F. Trochu, "Concurrent methods for permeability measurement in resin transfer molding," Polymer Composites, vol. 17, no. 1, pp. 149-158, 1996.

[11] K. Hoes, D. Dinescu, H. Sol et al., "New set-up for measurement of permeability properties of fibrous reinforcements for RTM," Composites A, vol. 33, no. 7, pp. 959-969, 2002.

[12] http://www.entropyresins.com/products/super-sap-1001000.

[13] R. Masoodi, R. F. El-Hajjar, K. M. Pillai, and R. Sabo, "Mechanical characterization of cellulose nanofiber and bio-based epoxy composite," Materials and Design, vol. 36, pp. 570-576, 2012.

[14] J. R. Vinson, The Behavior of Sandwich Structures of Isotropic and Composite Materials, CRC Press, 1999. 

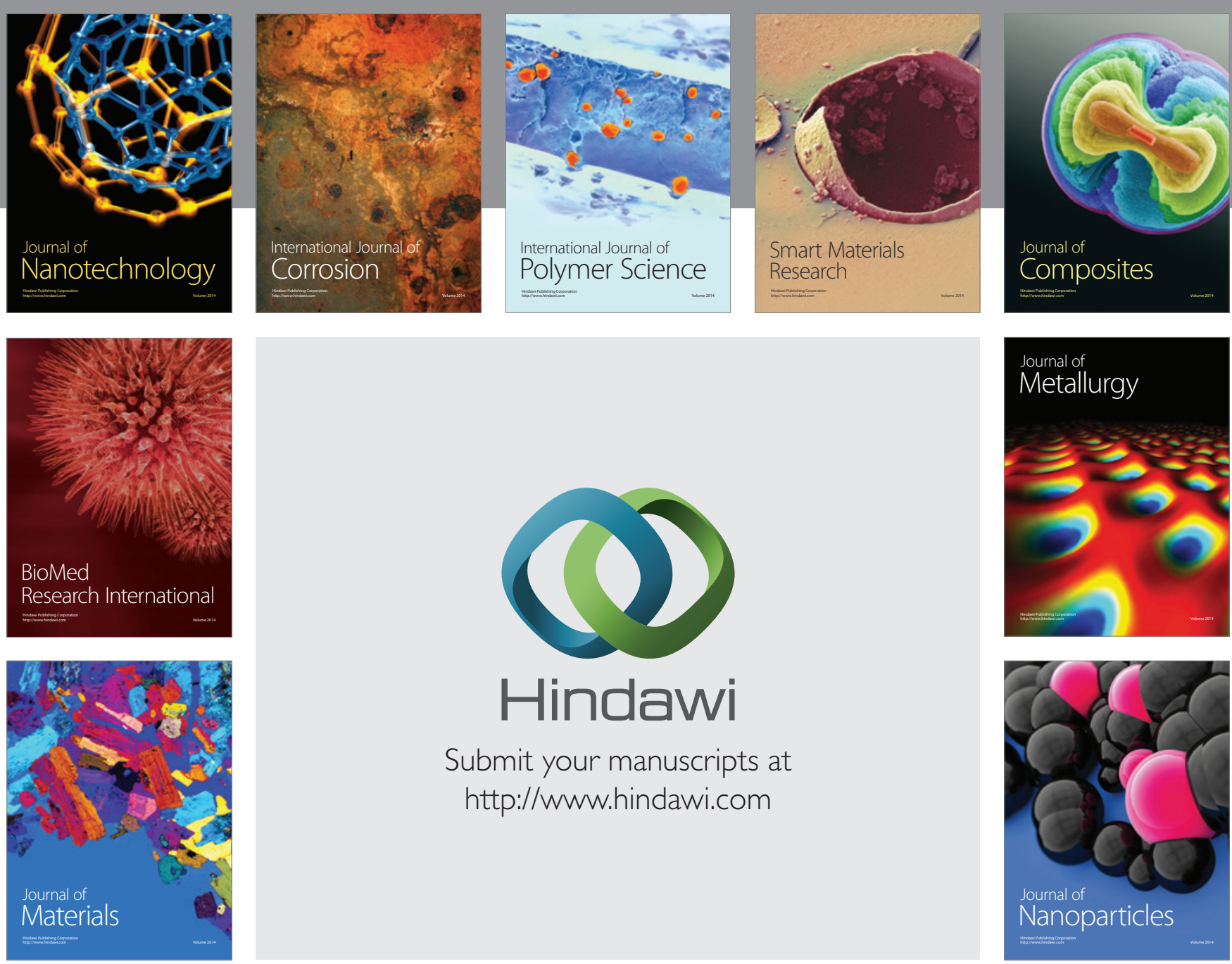

Submit your manuscripts at http://www.hindawi.com
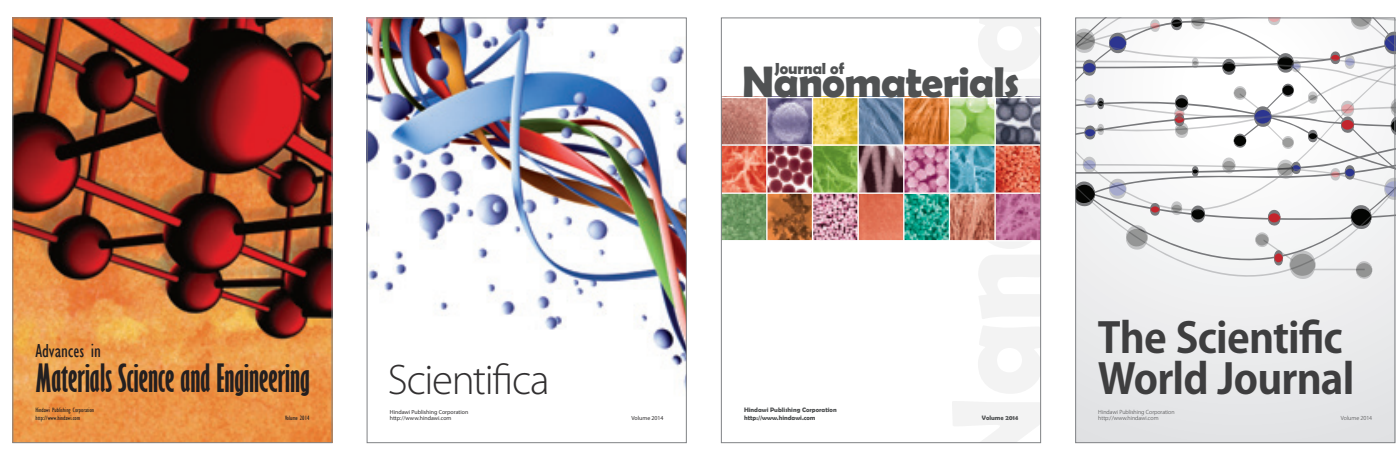

\section{The Scientific World Journal}
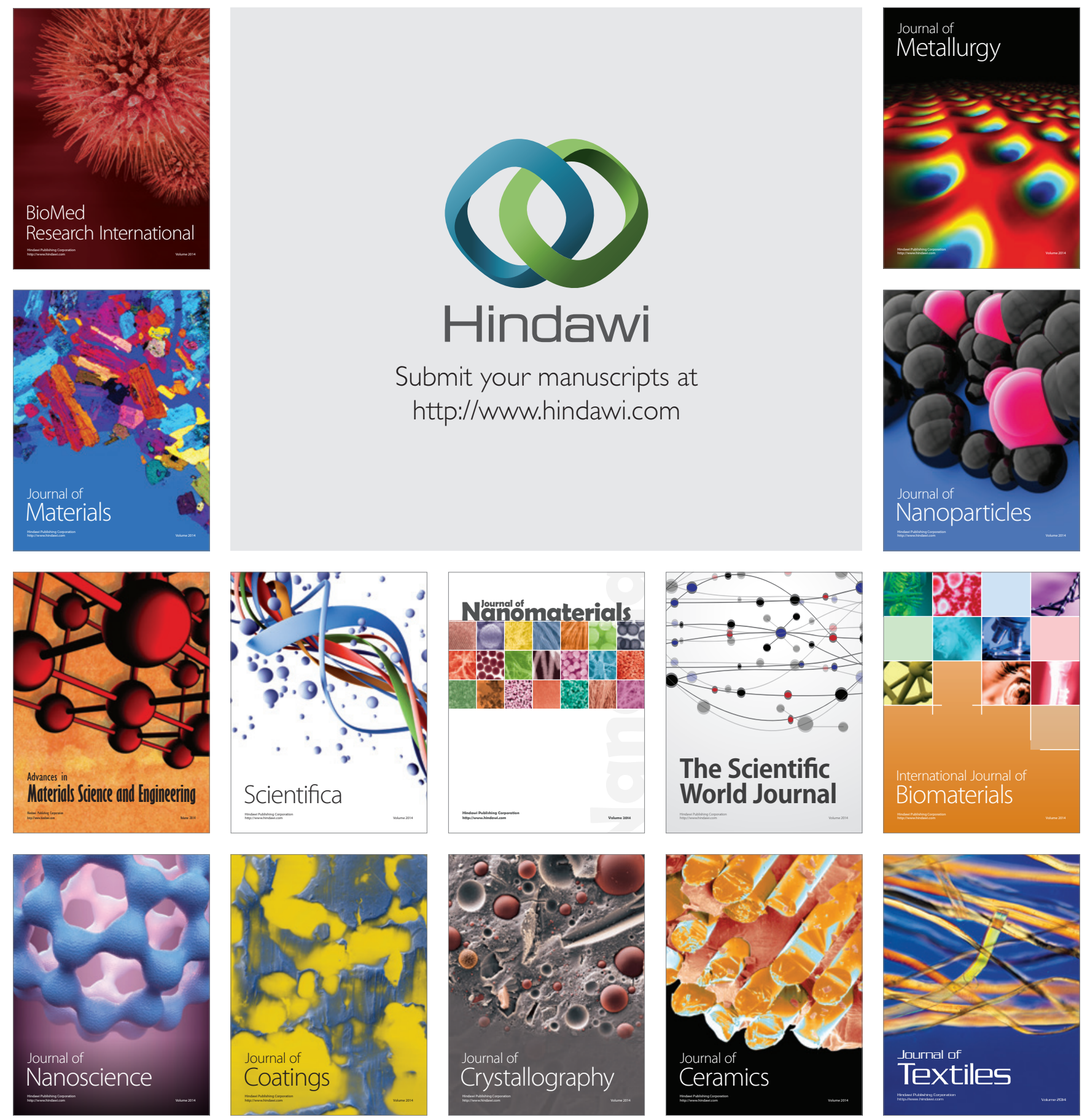